\title{
A CASE OF SITUS AMBIGUOUS AND COMPLEX CARDIAC DEFECT PRESENTING AS FETAL HYDROPS
}

\author{
Shagun Aggarwal
}

\begin{abstract}
Situs ambiguous comprises of $3 \%$ of congenital heart defects and is present in at least 1 in 10,000 live births. Most cases diagnosed prenatally are associated with complex cardiac defects which can be detected by ultrasonography. This is a case report of a fetus presenting with hydrops, which was detected to have situs ambiguous, a complex cardiac defect and multiple laterality defects on autopsy.
\end{abstract}

\section{INTRODUCTION}

Heterotaxy refers to any form of abnormal arrangement of thoracic and visceral situs; and includes situs inversus and situs ambiguous. Situs ambiguous is characterized by an abnormal arrangement of internal organs with discordance of thoracic and visceral anatomy and usually characterized by congenital anomalies[1,2]. It is a genetically heterogeneous entity, showing incomplete penetrance and variable expressivity. At least 8 genes and loci have been reported to be associated, with autosomal recessive, dominant and X-linked inheritance[3-10].In some instances, teratogenic influences like maternal diabetes and cocaine exposure have been found to be causative. Rarely laterality defects may be found in aneuploidies like trisomy 13,18 and 22q11.2 microdeletion syndrome[1,2].

This is a case report of a fetus brought for post-mortem evaluation in view of fetal hydrops and found to have situs ambiguous with complex cardiac defect.

\section{CASE REPORT}

This was the third pregnancy of a third degree consanguineous couple. First pregnancy was terminated at 32 weeks on detection of fetal hydrops. Fetal autopsy findings were reported as inconclusive. Second pregnancy resulted in a normal female child who was asymptomatic till 4month of age and attained appropriate milestones.

Article received on 04 APR 2017, published on 30 APR 2017.

Shagun Aggarwal ${ }^{1}$

${ }^{1}$ Asso.Prof, Department of Medical Genetics, NIMS, Hyderabad, India

Corresponding Author: Shagun Aggarwal

Email: shagun.genetics@gmail.com
This child expired with the onset of cardiomegaly and respiratory distress at 4 months age. In the present pregnancy at 27 weeks, hydrops was detected on an antenatal ultrasound done elsewhere, pregnancy terminated and fetus brought for autopsy. Family pedigree is depicted in Fig 1.

Fig 1: Pedigree of the family

\section{Pedigree}

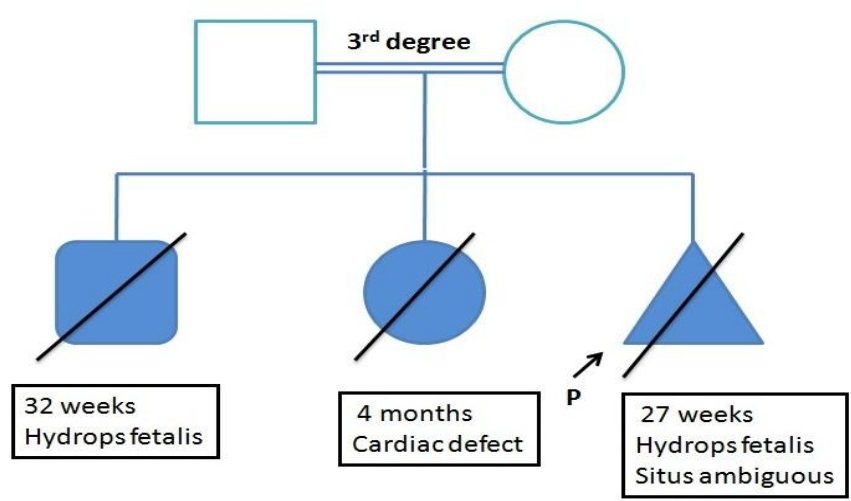

External examination revealed that thefetus was grossly hydropic with significant subcutaneous edema. Ears were large and dysplastic. There was no other external malformation or dysmorphism. External genitalia were normal female type. Placenta was not available for evaluation.

Anthropometry of the fetus revealed weight: $3.5 \mathrm{~kg}$ $(+13 S D$ for 27 weeks), Crown rump length : $28 \mathrm{~cm}$ (97th centile for 27 weeks), Crown heel length : $45 \mathrm{~cm}(+4 \mathrm{SD}$ for 27 weeks), Head circumference : 30cm (+5 SD for 27 weeks) and Foot length : $5.6 \mathrm{~cm}$ (95 ${ }^{\text {th }}$ centile for 27 weeks).

Intra-thoracic examination revealed an enlarged heart with Dextrocardia. There was an associated complex cardiac defect. A single atrium was present draining 4 pulmonary veins on the right side and two large vessels, likely Inferior vena cavas on both sides inferiorly. A single atrioventricular valve and single ventricular cavity was present. Both great arterial vessels arose sideby-side from this common ventricular cavity. 
Pulmonary artery was arising on right side and aorta on left with no crossing over. Aorta had an aneurysm (approx. $1 \mathrm{~cm}$ diameter) in the ascending arch. The descending aorta entered abdomen on left side. Blood mixed serous pleural effusion was present and both lungs were small looking. The diaphragm was normal. The esophagus was running on the left in thorax and crossing over to enter abdomen through right hemi diaphragm. Trachea appeared normal. Left lung had three lobes while right lung had two. Intra-abdominal examination showed presence of a midline liver. Spleen was present on the right side along with multiple small accessory spleens. Gall bladder was present in centre of liver. Stomach was present on right side. Abnormal rotation of colon was present. Bilateral kidneys, ureters, bladder and internal genitalia were normal. Intra-cranial examination could not be done due to autolysis of brain matter. Fig2 depicts the post-mortem findings.

Fig 2: Post-mortem findings of the fetus

a) Thoracic cavity depicting Dextrocardia. b) Inferior surface of heart showing two great vessels entering the atrium. c) Pulmonary veins draining into the atrium on right. d) Parallel great vessels with pulmonary artery on right and aorta on left. An aortic aneurysm also was seen. Three lobes of left lung and two lobes of right lung can also be appreciated. e) Single atrium and ventricle on cut section of heart. f) Hydropic appearance of fetusg) Midline liver. h) Stomach on right side, multiple spleens can also be appreciated on right of stomach i)Descending colon on the right side of abdomen
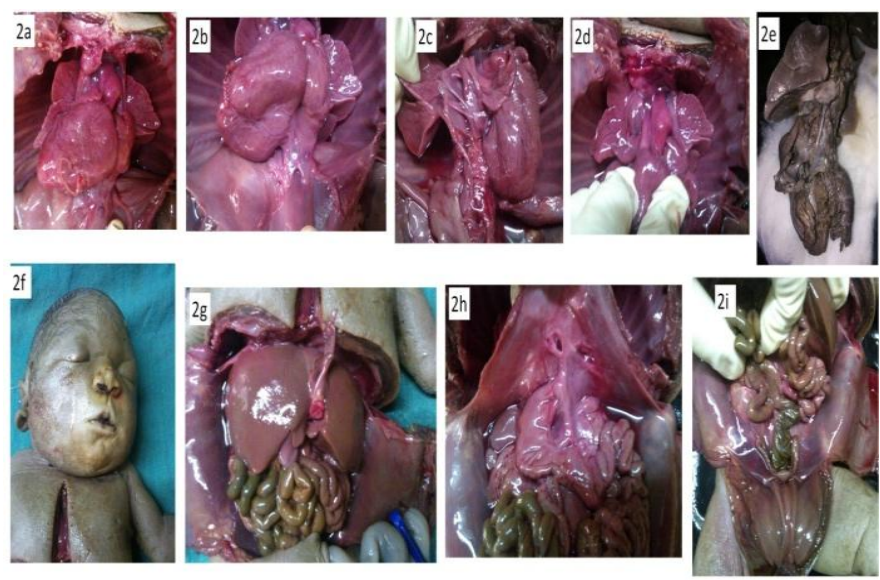

Karyotype of the fetus done from intracardiac blood was 46, XX. Enzyme assays for six lysosomal storage disorders known to cause fetal hydrops were normal. Fetal whole body radiograph did not reveal any skeletal abnormalities. Histopathology of fetal organs was inconclusive due to autolytic changes.

\section{DISCUSSION}

The post-mortem findings of this fetus are indicative of situs ambiguous with complex cardiac defect. The hydrops fetalis, which was the primary prenatal presentation, can be attributed to the cardiac defect. There is history of a previous fetus being affected with hydrops fetalis and an infant death with cardiomegaly, and it is plausible that both could have an underlying cardiac defect and other situs abnormalities, which were not ascertained. In view of consanguinity, spectrum of abnormalities in this fetus and possibility of similar affection of previous siblings, this appears to be an autosomal recessive situs ambiguous/heterotaxy syndrome with a $25 \%$ recurrence risk in subsequent conceptions.

Situs ambiguous/heterotaxy syndrome is a genetically heterogenous entity. At least eight genes and loci, namely ZIC3, NODAL, CFC1, HTX3, ACVR2B, PKD1L1, MMP21 AND CCDC11 are reported to be associated with this phenotype in various patients. Autosomal dominant inheritance has been documented for CFC1 and NODAL, autosomal recessive for PKD1L1,CCDC11 and MMP21 and X linked recessive inheritance for ZIC3 [3-10] In some patients, the molecular defects remain unidentified, and it is likely that more genetic loci may be identified in future using high throughput sequencing technologies. Identification of underlying genetic defects in these patients helps in appropriate genetic counseling and enables the provision of prenatal diagnosis by invasive testing in subsequent pregnancies as early as 11-12 weeks of gestation.

In the case reported here, the cardiac defect was missed on the antenatal sonogram and led to an unnecessary delay in pregnancy termination. This indicates the importance of detailed cardiac evaluation during antenatal sonography, especially for high risk pregnancies [10,11]. Additionally, a post mortem evaluation is very important for all such cases in the event of pregnancy termination, since it facilitates detailed anatomical delineation and identification of a syndromic etiology if any. In the present case, the additional findings of polysplenia, midline liver, gut malrotation and reversed lung fissures, are almost impossible to detect antenatally[11]. This is in 
concordance with literature reports which indicate that post-mortem evaluation can provide additional findings and lead to a change in diagnosis in $25-50 \%$ cases of antenatally detected malformations [12].

Antenatal diagnosis of situs ambiguous raises counseling challenges in absence of a cardiac defect. Many of these individuals may be clinically asymptomatic postnatally. On the other hand, some of the cases may have associated intellectual handicap or morbidities associated with missed abnormalities, like gut malformations, genitourinary abnormalities, etc [11]. In view of genetic heterogeneity, testing can comprise karyotype to exclude aneuploidies, chromosomal microarray to look for microdeletions/microduplications and high throughput sequencing based multigene panel testing to look for mutations in the genes reported to be causative. However, due to incomplete penetrance and variable expressivity for the monogenic forms, phenotypes of mutation carriers in the same family may range from completely asymptomatic to a complete situs ambiguous $[13,14]$. Hence, phenotype prediction in case of prenatal molecular diagnosis remains difficult in this rare group of defects. In the reported case, no molecular testing could be performed, and hence prenatal diagnosis can be attempted by ultrasound only in subsequent pregnancies.

To conclude, this is a case report of a fetus presenting with hydrops, subsequently diagnosed with situs ambiguous with complex cardiac defect on autopsy, and possible autosomal recessive inheritance in family.

\section{Acknowledgments}

I acknowledge the contribution of Dr. Ashwani Tandon, Associate Professor, Pathology, Nizam's Institute of Medical Sciences, who helped in histopathological evaluation of fetal organs.

\section{REFERENCES}

1. Zhu L, Belmont JW, Ware SM. Genetics of human heterotaxias. Eur J Hum Genet. 2006 ;14(1):17-25.

2. Sutherland MJ, Ware SM. Disorders of left-right asymmetry: heterotaxy and situs inversus. Am J Med Genet C Semin Med Genet. 2009;151C(4):307-17.

3. Gebbia, M., Ferrero, G. B., Pilia, G., Bassi, M. T., Aylsworth, A. S., Penman-Splitt, M., Bird, L. M.,
Bamforth, J. S., Burn, J., Schlessinger, D., Nelson, D. L., Casey, B. X-linked situs abnormalities result from mutations in ZIC3. Nature Genet. 1997; 17: 305-308.

4. Bamford, R. N., Roessler, E., Burdine, R. D., Saplakoglu, U., dela Cruz, J., Splitt, M., Goodship, J. A., Towbin, J., Bowers, P., Ferrero, G. B., Marino, B., Schier, A. F., Shen, M. M., Muenke, M., Casey, B. Loss-offunction mutations in the EGF-CFC gene CFC1 are associated with human left-right laterality defects. Nature Genet. 2000; 26: 365-369.

5. Peeters, H., Debeer, P., Groenen, P., Van Esch, H., Vanderlinden, G., Eyskens, B., Mertens, L., Gewillig, M., Van de Ven, W., Fryns, J. P., Devriendt, K. Recurrent involvement of chromosomal region $6 \mathrm{q} 21$ in heterotaxy. Am. J. Med. Genet. 2001; 103: 44-47.

6. Kosaki, R., Gebbia, M., Kosaki, K., Lewin, M., Bowers, P., Towbin, J. A., Casey, B. Left-right axis malformations associated with mutations in ACVR2B, the gene for human activin receptor type IIB. Am. J. Med. Genet. 1999; 82: 70-76.

7. Vetrini, F., D'Alessandro, L. C. A., Akdemir, Z. C., Braxton, A., Azamian, M. S., Eldomery, M. K., Miller, K., Kois, C., Sack, V., Shur, N., Rijhsinghani, A., Chandarana, J., and 12 others. Bi-allelic mutations in PKD1L1 are associated with laterality defects in humans. Am. J. Hum. Genet. 2016; 99: 886-893.

8. Narasimhan, V., Hjeij, R., Vij, S., Loges, N. T., Wallmeier, J., Koerner-Rettberg, C., Werner, C., Thamilselvam, S. K., Boey, A., Choksi, S. P., Pennekamp, P., Roy, S., Omran, H. Mutations in CCDC11, which encodes a coiled-coil containing ciliary protein, causes situs inversus due to dysmotility of monocilia in the leftright organizer. Hum. Mutat. 2015; 36: 307-318.

9. Guimier, A., Gabriel, G. C., Bajolle, F., Tsang, M., Liu, H., Noll, A., Schwartz, M., El Malti, R., Smith, L. D., Klena, N. T., Jimenez, G., Miller, N. A., and 24 others. MMP21 is mutated in human heterotaxy and is required for normal left-right asymmetry in vertebrates. Nature Genet. 2015; 47: 1260-1263.

10. Salomon LJ, Alfirevic Z, Berghella V, et al. Practice guidelines for performance of the routine mid-trimester 
fetal ultrasound scan. Ultrasound Obstet Gynecol. 2011 Jan;37(1):116-26.

11. Abnormalities of Fetal Situs: An Overview and Literature Review. Obstet Gynecol Surv. 2016 Jan;71(1):33-8.

12. Rodriguez MA, Prats P, Rodríguez I, et al. Concordance between prenatal ultrasound and autopsy findings in a tertiary center. Prenat Diagn 2014 Aug;34(8):784-9.
13. Chung, B., Shaffer, L. G., Keating, S., Johnson, J., Casey, B., Chitayat, D. From VACTERL-H to heterotaxy: variable expressivity of ZIC3-related disorders. Am. J. Med. Genet. 2011;155A: 1123-1128.

14. Chhin, B., Hatayama, M., Bozon, D., Ogawa, M., Schon, P., Tohmonda, T., Sassolas, F., Aruga, J., Valard, A.-G., Chen, S.-C., Bouvagnet, P. Elucidation of penetrance variability of a ZIC3 mutation in a family with complex heart defects and functional analysis of ZIC3 mutations in the first zinc finger domain. Hum. Mutat. 2007; 28: 563-570. 